\title{
Several Opinions on Effects of Insulin, Metoprolol and Deferoxamine on Fat Graft Survival
}

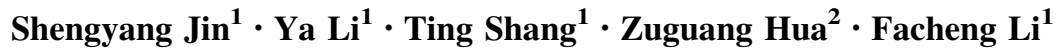

Received: 29 May 2019/Accepted: 30 May 2019/Published online: 11 June 2019

(C) Springer Science+Business Media, LLC, part of Springer Nature and International Society of Aesthetic Plastic Surgery 2019

Level of Evidence $V$ This journal requires that authors assign a level of evidence to each article. For a full description of these Evidence-Based Medicine ratings, please refer to the Table of Contents or the online Instructions to Authors www.springer.com/00266.

Sir,

We read with great interest the article entitled "Effects of Insulin, Metoprolol and Deferoxamine on Fat Graft Survival" by Okyay et al. [1] in Aesthetic Plastic Surgery. The authors found that the three drugs did not exert a significant influence on fat graft survival.

The fat grafts treated with three kinds of drugs and the control group were implanted into the back of the rat. We are concerned that implanting different drugs on the back of one rat would result in drug absorption by the body and interfere with other groups.

In this study, the inguinal fat pads were split into four nearly equal parts as grafts. However, there would be a larger contact area between the grafts and the drug if the grafts were dissected into small pieces. Both shredded fat grafts and fat mass transplantation have been reported in the literature $[2,3]$, whose outcome may be different.

Facheng Li

drlifc@sohu.com

1 Plastic Surgery Hospital (Institute), Chinese Academy of Medical Sciences, Peking Union Medical College, No. 33 Badachu Road, Shijingshan District, Beijing 100144, People's Republic of China

2 Ningbo No1 Hospital, No. 59, Liuting Street, Haishu District, Ningbo 315000, Zhejiang, People's Republic of China

\section{Compliance with Ethical Standards}

Conflict of interest The authors declare that they have no conflicts of interest to disclose.

\section{References}

1. Okyay MF, Kömürcü H, Bağhaki S et al (2019) Effects of insulin, metoprolol and deferoxamine on fat graft survival. Aesthet Plast Surg 43(3):845-852

2. Liu K, Cai J, Li H et al (2018) The disturbed function of neutrophils at the early stage of fat grafting impairs long-term fat graft retention. Plast Reconstr Surg 142(5):1229-1238

3. Shi N, Su Y, Guo S et al (2019) Improving the retention rate of fat grafts in recipient areas via botulinum toxin A treatment. Aesthet Surg J. https://doi.org/10.1093/asj/sjz073

Publisher's Note Springer Nature remains neutral with regard to jurisdictional claims in published maps and institutional affiliations. 